Historic, Archive Document

Do not assume content reflects current scientific knowledge, policies, or practices. 

- THE - 1926 - MESSAGE -

\section{THE VANDERBILT HYBRID DELPHINIUMS}

San Rafael, California

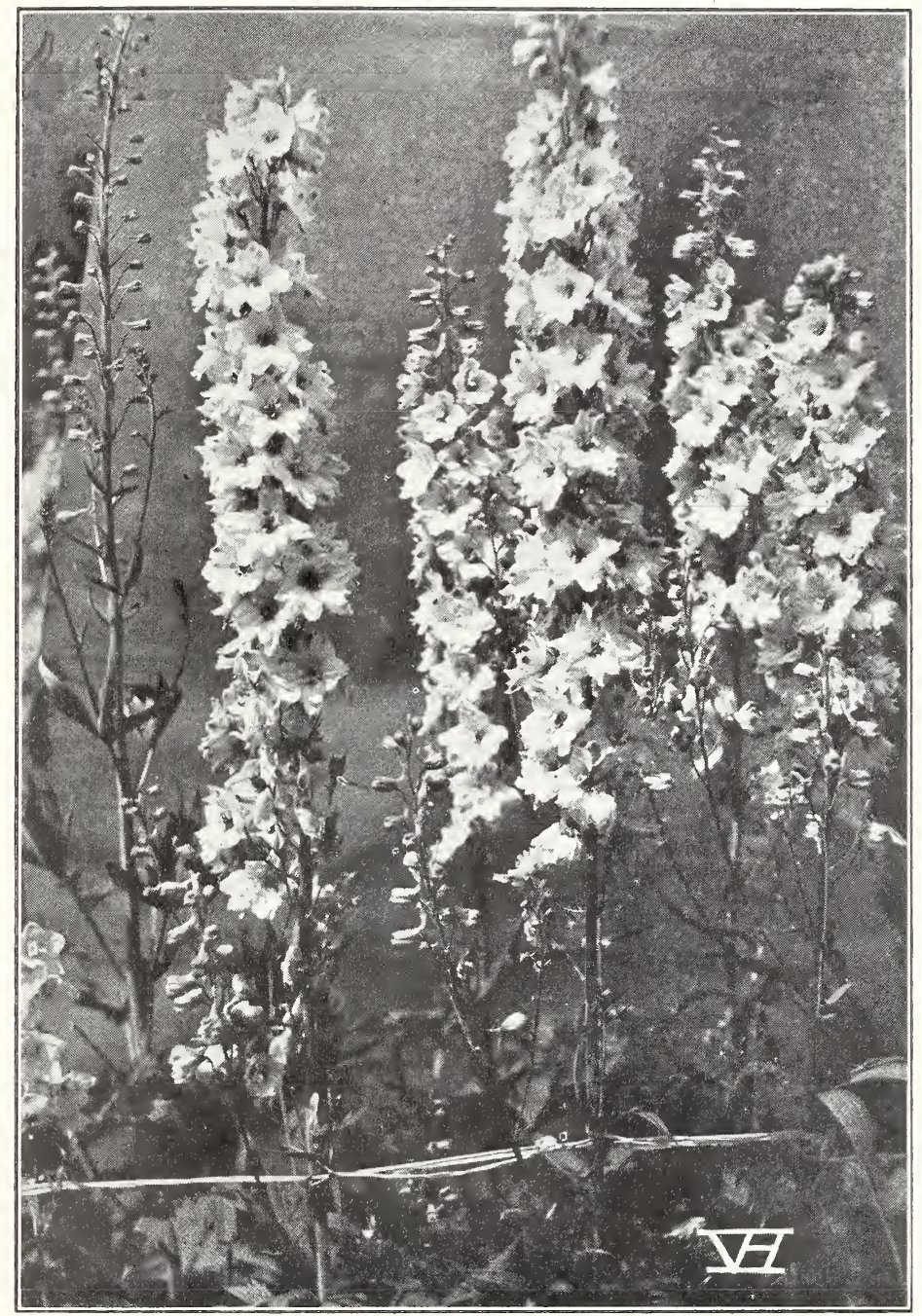

A VH TYPE PLANT, 2nd Year

Double, Ruffled, Pastels Pink-Blue; 34 in., 5 ft.

To The VH CIRCLE, Greetings:-

This is not a catalogue, but listed as our eighth annual message to the VH CIRCLE, concerning new developments in the strain, new promises indicated, and 


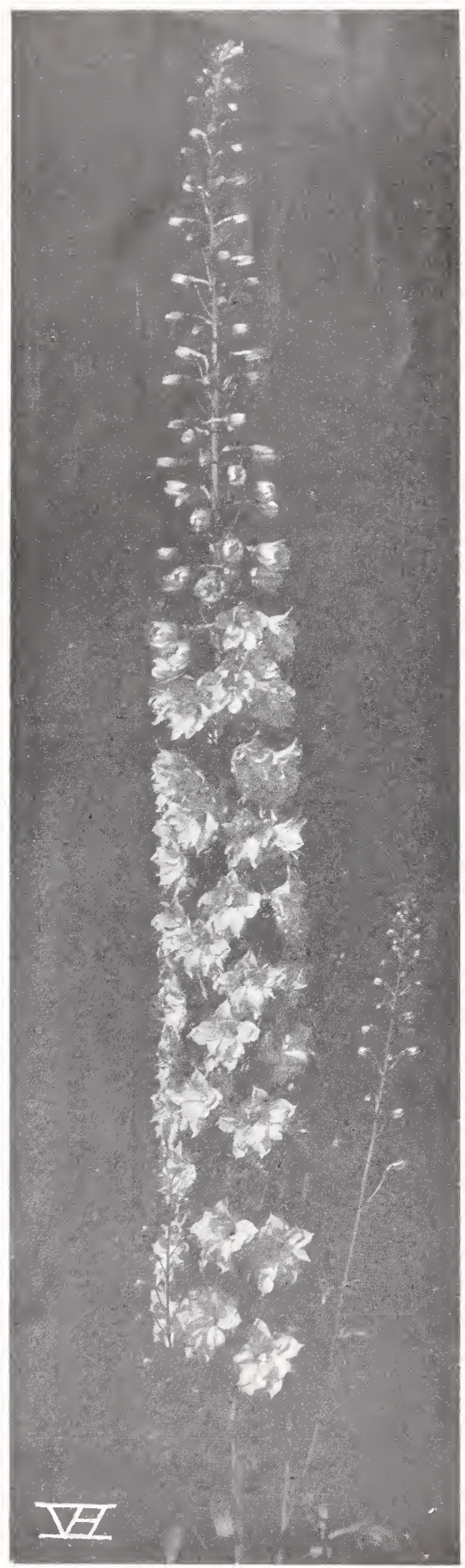

supplies list available first to our Circle members. We especially appreciate the evidences of personal recommendation of our seeds and plants in Garden Associations and Garden Sections of Federated Woman's Clubs circles, which are virtually leading American gardening activities today. These advances have placed VH far beyond first plans, as indicated on page 2 sections roster. If any reader has a flower friend in either of the two states not listed, or in a country not shown, we shall appreciate the reference, desiring to have $\mathrm{VH}$ tested in every climatic environment possible.

Our Strain.-Our aim for something "different" in Delphiniums has met a growing demand for balanced artistry of form, habit and beautiful colorings in these flowers, true indication we believe, of lasting appreciation of its beauty. Our best recommendation appears to be the regularly repeating orders of long time patrons in nursery, florist and fancier circles, - competent judges of merit types. Now the more intensive gardening folk, - the ladies, - are analyzing our claims and welcoming the sheer beauty and balance of form and coloring making up the quiet dignity of exquisite things in the strain. It's outstanding merit, experts tell us, is the constant "up-grade" tendency toward betterments in successive year plantings, said to be a most rigid test of breeding and development practices.

In Appreciation.-Having separately collected seeds of several thousand plants for analysis of seed vitality breeding results, we are enabled to this year, offer variety of choice for amateur, fancier and specialist in the new things, - we believe the first time such an offer has been open to growers. In this way only, can we in turn favor the VH Circle for past courtesies to us.

SYMMETRY HYBRIDS TYPE

58 in stalk; 44 in spike

(Rurbank $\times$ D scopolorum x D cardinalis) 
“ C A THEDRAL SPIRES

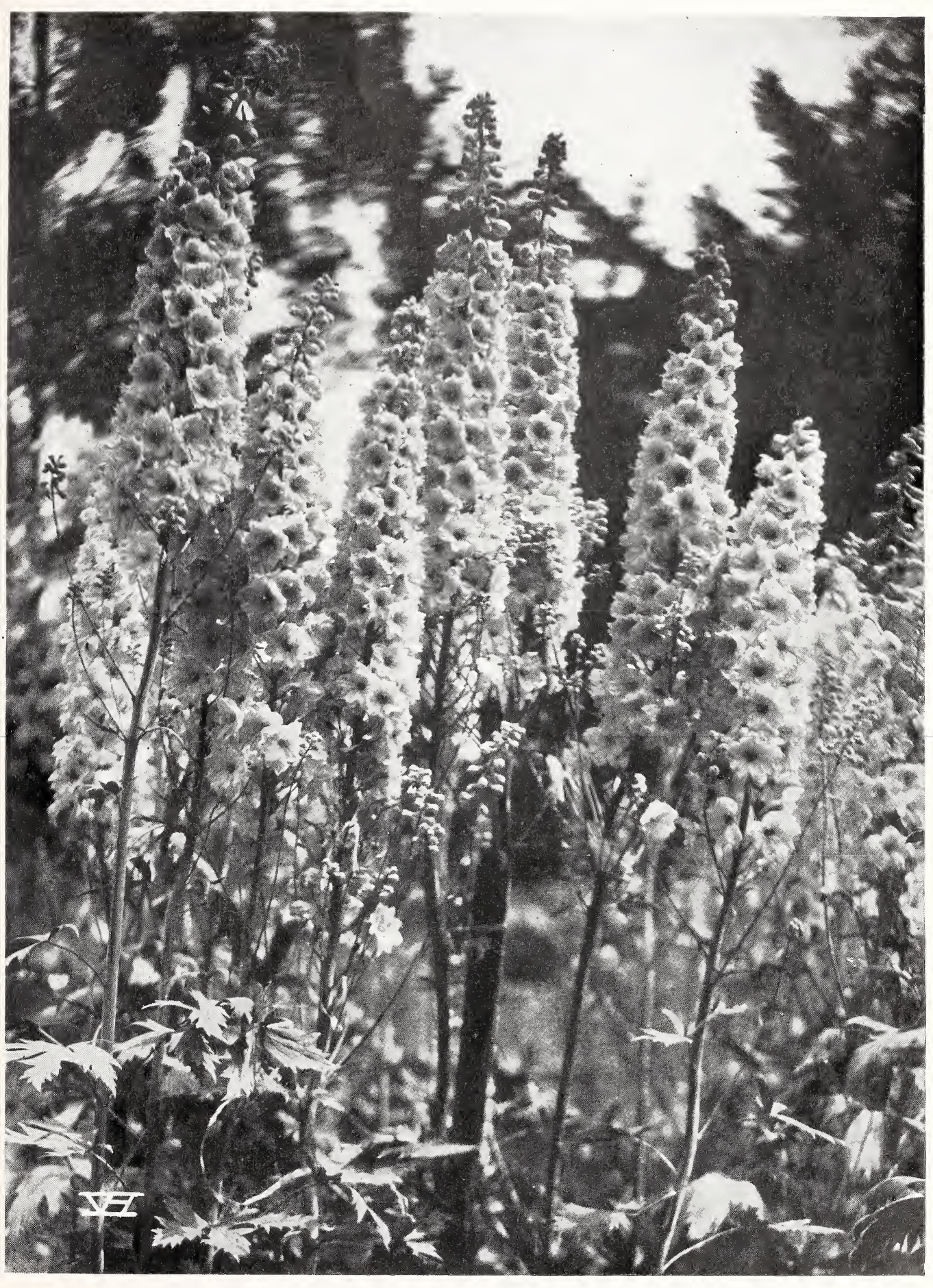

The "LILLIAN MURRAY"

An 8 spike, 2nd yr. plant; 32 in., $7 \mathrm{ft}$. 3 row double, soft Alice Blue with rose centering. 


\section{"HYACINTH DELPHS"}

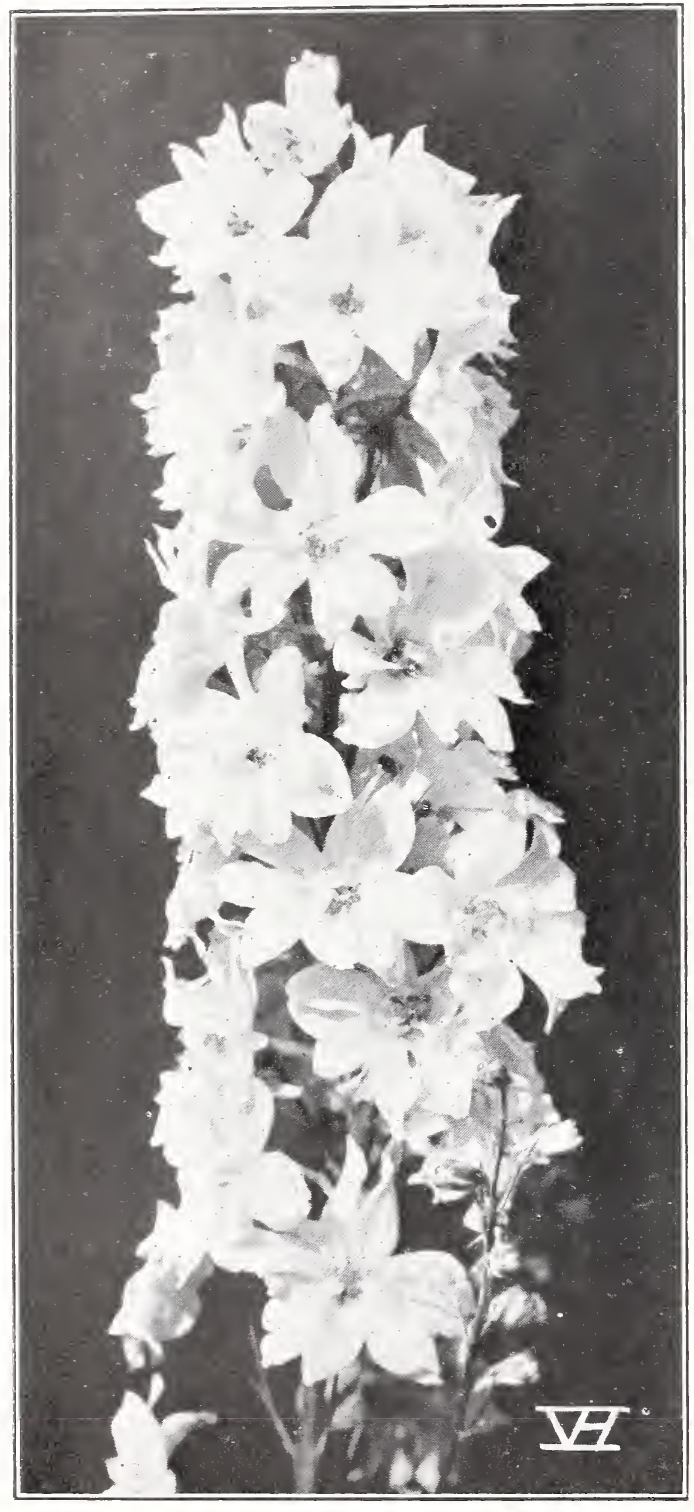

An "EMILY TAYLOR" Seedling The "All-Out-Together" VH type in tinted ivory, with hint of blue.

\section{ARE VH HARDY? NOTE WHERE THE GROW:}

AMERICA

$\begin{array}{ll}\text { Alabama } & \begin{array}{l}\text { Missouri (20) } \\ \text { Nrizona }\end{array} \\ \text { Nebraska } \\ \text { California (102) } & \text { Nevada } \\ \text { Nolorado } & \text { Newanpshire } \\ \text { Connecticut (25) } & \text { New York (77) } \\ \text { Delaware } & \text { North Carolina } \\ \text { DistrictColumbia } & \text { North Dakota } \\ \text { Florida } & \text { Ohio (28) } \\ \text { Georgia } & \text { Oklahoma } \\ \text { H.T. } & \text { Oregon (20) } \\ \text { Idaho } & \text { Pennsylvania } \\ \text { Illinois (45) } & \text { P. I. } \\ \text { Indiana (20) } & \text { Rhode Island } \\ \text { Iowa (21) } & \text { South Carolina } \\ \text { Kansas } & \text { South Dakota } \\ \text { Kentucky } & \text { Tennessee } \\ \text { Louisiana } & \text { Texas } \\ \text { Maine } & \text { Utah } \\ \text { Maryland } & \text { Vermont } \\ \text { Massachusetts } & \text { Virginia } \\ \text { (46) } & \text { Washington (23) } \\ \text { Michigan (22) } & \text { W. Virginia } \\ \text { Minnesota } & \text { Wisconsin (21) } \\ \text { Mississippi } & \end{array}$

\section{CANADA}

$\begin{array}{ll}\text { Alberta } & \text { Ontaria (2t) } \\ \text { British Columbia } & \text { P. E. I. } \\ \text { Manitoba } & \text { Quebec } \\ \text { N. Brunswick } & \text { Saskatchewan } \\ \text { Nova Scotia } & \end{array}$

ABROAD

$\begin{array}{ll}\text { Australia } & \text { Italy } \\ \text { Checkos } & \text { Japan } \\ \text { China } & \text { Nexico } \\ \text { Egypt } & \text { Norway } \\ \text { France } & \text { New Zealand } \\ \text { England } & \text { South Africa } \\ \text { Germany } & \end{array}$

NOTE-Figures show 20 and over cities and towns, indicative, we believe, of activities of Garden Club Circles territory. 


\section{"BETTER METHODS"}

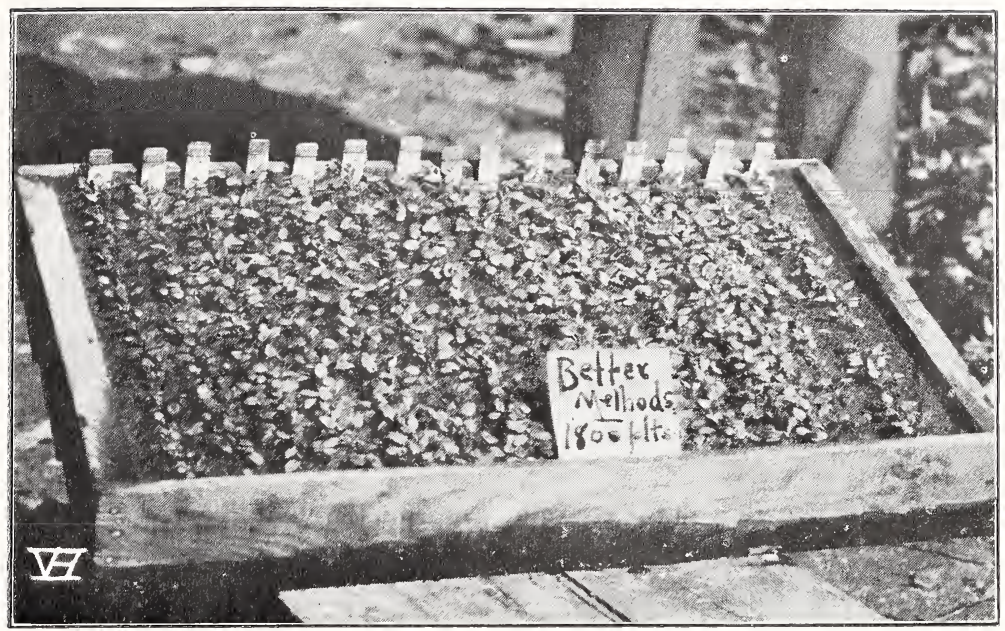

A VH "NO LOSSES" METHOD

SEED TO SEED SUGGESTIONS.-We prefer box germination after testing other ways-in frames, under glass and in beds. Commercial plantings could adapt it to needs, with much better results in numbers and standard of plants maturing. It removes handicaps of poor ventilation, surface winds or changes of air, temperature and surface moisture, excess humidity, cut worm, slug, damping off, mildew, etc., troubles affecting seedlings here and there,- by reason of instant note of and remedy for them. This tides over the most critical plant stage, - the seed leaves period, and allows constant soil stirring for seedlings. For amateurs we suggest: (1) choose your specialist and obtain his seeds. First plan all details of sowing. Many prefer half first, then remainder as these appear, so as to check methods. (2) Sandleafmold, or sand-grassroots loam supplies good seed box material, if well drained and decayed refuse at bottom to retain moisture. (3) Leave an inch space at box top. Wet thoroughly, fill at once, smooth and firm, sow thickly in rows, and merely press in seeds with flat surface. This plants all equal depth. Just cover with fine light humus (moisture holding soil) and press again. Secret of Delphinium seeds germination is low, steady temperatures, absence of drafts (drying effects), steady surface moisture (insured this way till plantings show), and darkness. Place box in shade, north of fence, in cellar or cover with box or burlap but insure ventilation. They appear in 10-15 days, at times earlier in cool periods. Bring to light and for a time in cooler sunlight hours only. Very susceptible to damping off. We spray with Qua Sul at first showing and intervals thereafter (1-200) and never have it. We note new remedies of "Uspulin" and "Semesan" and Mercuric Chloride are recommended also for such fungus troubles. Reflat or replant in frames as soon as second leaves appear. Difficulties through root branching occur thereafter. Shade these plants a day or two. For soil, add enough loam to former to make firmer, insure drainage, bottom refuse for moisture, and add bone meal, woodashes or both at bottom for later root supply. If in Fall, grow in flats to dormancy, even to large plants. In cold climates mulch heavily or bury boxes, allow to freeze solid but prevent alternate freezing and thawing. Remove mulch when tips show, grow to several leaves and field about six inches apart. Stir soil constantly, water copiously, enjoy blossoms by cutting ALL as soon as first crop flowers, and await the quick coming summer new set. Spring sown seeds 
bloom here in 130-150 days and Fall seedlings in March-April, the latter giving much stronger, better succession plants in fine bedding show. Qua Sul sprinkled along seedlings rows kills cut worm and prevents slug attacks. Marked tendency of VH strain is succession growth, hence cut back as petals fall. Let the other fellow "ripen" his one-a-season stalks. Qua Sul spray 1-200 or stronger if mildew gains foothold, destroys any delph fungus trouble such as mildew, rust, leaf spot, blight, etc., and should be tried with Wright Formulae (lime and nicotine), the Cornell Mercury solution or ANYTHING RECOMMENDED, for the dreaded Black Rot troubles in some quarters. We invite growers to address us in plants successes and failure matters, so that all may gain thereby.

THE VH HISTORY.-Visioned history of a plant lends added charm to its culture, hence new Circle members should know how VH started. While camping one summer amidst the great Sierran display of D. scopolorum, we visioned the time when some plant breeder could work these inimitable types into garden forms,-they being far superior in artistry of spike and flower than then known. We next grew Burbank flowers, and when he announced that "tendencies to vary were transmitted to progeny along with basic heredity characters," we planned idle hour experiment in variations with Delphiniums. We reasoned that $D$. scopolorum, luxuriating where the oldest living things remained untouched by the Ice Age devastation elsewhere, probably had the ideal in fixed dominant qualities of habit and form, whilst the then new sizes and beautiful new colorings of Burbank types gave ideal variables therein, as well as in marked succession of bloom. We planned building a plant habit first, then attempting to attach the finely decorative trimmings Mr. Burbank had brought to garden hybrids. So we crossed the two in 1912, recrossing selections in 1914. Most promising results followed in resistance, vigor and succession, as well as daintier form and coloring. They were exhibited at a California State Floral Society exhibition and gained first prize, the good ladies thereof urging continuance of the work. Then a 200 spike exhibit brought in the Michael Medal. Next, the badly needed blue tones in the Panama-Pacific International Exposition gardens came from Vanderbilt's all summer while others failed, and both garden and cut flower Delphinium Medals came to our developing strain. Thus we officially "arrived" in flowerdom. Some 80,000 crossed and selected seedlings have since been used in the work, retaining only those which approached a ten quality per plant standard aimed for. VH is now said to be the only existent "pure bred" strain, since rigid exclusion of other types was necessitated in its development, and such steadily improving standards proceed that we consider it unwise to introduce even finest other things as yet. $\mathrm{VH}$ have, however, been invaluable aids to others for breeding purposes, there being now six commercial strains based on selections from $\mathrm{VH}$. We raised seeds for several years for widespread distribution by both an Eastern and a Western seed house, who brought the new things to Eastern and Canadian attention. Later we assumed personal responsibility, and page 12 hereof indicates present scattering of our results. An outstanding merit of the strain is its constant "up grade" tendency on successive plantings, partly explainabla by the annual weeding out here of older sorts and addition of the finest new things from new experiments and selections. Its remarkable percentage of perfectly beeed doubles and definite resistance factors have been widely commented upon, and now the steadily maintained large flower sizes are winning awards in many quarters. IVe appreciate note of these recognitions for they guide our endeavors here. When you hear "Its a Vanderbilt," let us know about it and describe the flower. In 1915, Dr. Babcock, Univ. Calif. Bot. Dept., sent us crossed D. cardinalis seeds. They proved to be "fixed" though several years, and a recross was made here, both series being developed. Self purples still persist in the Babcock series while the others vary widely. To him, however, belong the credit of first visioning the rare value of $D$. cardinalis hybrids. Aside from valued characters of slenderness and minimum foliage, we considered possible a strong intensification of coloring through these scarlet Californians, and thereby have gained rich, deep shadings and self colors never before mentioned in Delphinium literature. Difficult indeed it is to remove the biue dominance, but slowly the promise of pure crimson approaches completion, whilst wonderful things are constantly evolved. No such vigor, quick and 
repeated growth, uniformly tall stalks and fine spikes, or wide range of coloring has been seen before in thousands of plants here. This year we separate it into exquisite new singles (No. 1600 ), doubles (No. 900), and the more gorgeous J. W. Schlosser variation (No. 5300). They account for many of the supposed "pure sports" reported to us by amateurs from our past season seeds, and now in selection will please even better. We especially ask reports from these. (3) In 1923 we found distinct variation in the low, spring flowering native $D$. nudicale. That started us to hunt for the "fabled" pure D. coccinea of early coast botany record. We believe we found it, likewise a fine yellow, - var. lutea, perhaps a D. decorum form. Intercrossings of all three have given wonderful ranges of orange, cerise scarlet, crimson, light and deep blues, royal purples, - even muddy whites to complete the cycle. If they perpetuate themselves, an exquisite and ideal spring pot plant type is born, for innumerable short spikes throw wonderfully bright and lasting flowers for a long period under cool conditions. Thus closes the triangle. We have "created" nothing. We have taken the work of more experienced folk and carried it into untried fields, and in the pleasures derived from reports of the new delphs succeeding where such plants never grew before is the great reward in working things out for Delphinium betterments.

NEW PROMISES.-With the small quantity of seeds available, the newest things are added in usual mixtures for the "surprises" day later in many gardens. "I have gone out every day to see if these beautiful things remain true," writes an experienced Delph fan. "Thus carries the message of Vanderbilt "Different" Delphiniums. Attempts at straight line varigations evolve something exquisitely better in beautiful picotee (No. 8200) effects and strangely in large doubled flowers only,such as tinted ivory, of blue, sharply defined, edges; deep navy, brilliant crimson edges; bright azure, flamed fuchsia purple, and aster petalge soft blue with pink rib. The parallel-to-stalk-pedicel double types have taken on exquisite ruffling, and immeasureably add to artistic grace of spikes. The clear pinks fade in direct sun unless heavily irridiscent and are being selected thereto. In the mauve section, no less than 104 plants in self shades from mauve-lilac-mouse-lavender-plum and purple have come from from D. cardinalis crosses, evidently antagonistic to shadings, and make up a remarkable collection in new things. In aster petalage (long, narrow), "wheel" flowers, we advance to two and a fourth inch blossoms of wonderful effect but as yet fair spikes only. No. 8300 gives us long desired brilliant, irridiscent, self, doubled blues with snow white bees, but are yet shy seeders. The Burbank memories in clear pink and blue have wonderfully advanced and 1927 sees their segregation in No. 8100. New visions of sheer beauty in this flower come with progressing orange, yellow and buff bees on deep blues, belladonna shades and especially tinted light blue singles (No. 3400). New forms of thickened petals in Nos. 1700 and 3900 promise exceptional delicacy of fast colors and bee combinations, whilst No. 2500 is a departure from 1700 in brilliant azure with inner fuchsia,--a new combination here. We finally have deep blue and light blue in same flower, likewise, a self blue with clear cerise pink circular bee of many petals, forerunner we believe of candidates for the Prescott Medal. Lastly,-and we decline to be excited about it,- - a second and third type of fragrance occurs in many plants, only one lily - like now, two pleasantly spicy, and numbers with strong vanilla like scent confined to but one form in single, tinted sky blues with grey-brown eyc. In another garden we found VH fragrance in deep blue and a self violet of the same series. We ask that all now search for such evidences and write us reports thereon. They have thus far appeared in Illinois, Minnesota, Maryland and Oregon. Easily noted in a cut bloom bouquet. Such reports will receive the first Vanderbilts in the selected new "Delphinium odorata" when available.

OUR AIM is constantly toward extreme hardiness first, plant habit second and balanced perfection third. We urge three things for the amateur: Care for the seeds properly. They will NOT deteriorate at low, steady temperatures, if free from drafts or humidity changes. If seemingly dry, swell between blotting pads, dry enough to handle, and plant promptly. Secondly, if necessary for room, discard the quick growing seedlings and coax along the slower ones. In them lies the greatest promise. Water seedlings copiously and keep ground stir- 
red constantly. While many things may happen to prevent proper seeding results, we guarantee replacements on notice, except in large plantings, for any failure in proper germination or quality standard. Occasional impositions result, but the earnest planter profits.

BETTER DELPHINIUMS MAGAZINE is NOT a VH connection other than edited by Mr. Vanderbilt, as a means of all learning about the world's best, culture, troubles. remedies, and growers exchange items. Address all communications to "Better Delphiniums," 230 Vay View St., San Rafael, California. Subscription, April and October, $\$ 1.00$. Numbers $4,5,6,7$ available in small number at $75 \mathrm{c}$ each, or $\$ 1.00$ for two.

\section{SUPPLIES LIST \\ THE VANDERBILT HYBRID DELPHINIUMS \\ FALL, 1926}

We cannot guarantee colors Line bred plants' seedlings closely resemble parents; newer ones vary slightly. By our "types" plan averages greatly increase with 10-100 plants of the series closely resembled to basic selection usually named or numbered for naming-represented. Keep seeds wrapped in cotton and wax paper unti? planting. Prevents humidity changes damage. 'The VH Circle increases rapidly. hence order to reserve early. The Specials seeds are hand cleaned, and mixed separately as ordered, hence added cost. The quantity is limited, $80 \%$ of all best sorts: are in general mixture to protect larger planting standard. All seeds are 1926 crop.

SEEDS. (1) Vanderbilt Mixture, about 5000 selections (not merely a freld seeds collections) from 80,000 crosses and selections in a pure bred strain. For nursery, commercial cut bloom and larger plantings, ounce, $\$ 3.00$; trade pkt. 500 seeds, $50 \mathrm{c}$. Light or dark shades increased at request.

(2) Vanderbilt Specialist Packet, about 300 seeds, $\$ 1.00$. Represents about 1000 plants, leaders in all types series.

(3) Vanderbilt Special Mixtures, in light shades, dark, pink-blue, or doubles or singles only. about 300 seeds, $\$ 2.00$.

(4) Vanderbilt Fanciers' Group of 15 types packets, about 1200 seeds, $\$ 4.00$, in 10-100 plants each, closelv resembled.

(5) Vanderbilt Franciers' Types. Those marked * NOT available. 50 c each, five $\$ 2.00$, from $100-200$ seeds each.

(6) The Vanderbilt Exhibitions Group, 100 plants, chosen for best spikes, vigor, succession, beauty and resistance, mixture about 300 seeds, $\$ 3.50$; ten of each. mixed (about 1000 seeds) $\$ 7.50$.

(7) Vanderbilt Developing Types, still variable, Nos. 900, 1600, 1700, $2500,3700,3900,4700,5300$, 9500, trial each 25c; five, $\$ 1.00$.

Note replacement guarantee for failure of standard germination or results in packet lots.

PLANTS. Limited in quantity, for Fall delivery. Cold storage, spring delivery, additional cost. We can supply in quantity for larger planting, mixed. Prices include delivery in U. S. Canadian orders must have permits.

(1) $1 \mathrm{yr}$. clumps, strong crowns, bloomed, mixed, \$2.75 the dozen.

(2) 2 and 3 yr. clumps, strong crowns, labeled main color, $\$ 3.75$ mixed.

(3) 2 and 3 yr. clumps, selected sorts tested, labeled, mixed, $\$ 5.00$.

(4) 2 and 3 yr. smaller clumps, strong roots only, lost labels, extras, etc., $\$ 2.25$ the dozen. Half dozen lots, dozen rate plus 50 cents.

PLEASE send us card report of VH you have germinated, or previously grown or seen, and add names of friends who may be interested in this Message.

725 Fifth Ave., San Rafael, Calif.

Gardens at Belle and Union Sts.
JOHN W. SCHLOSSER

NEWELL F. VANDERBILT 